\title{
Proficiência digital de professores: competências necessárias para ensinar no século XXI
}

\author{
Josiane Brunetti Cani ${ }^{1}$ \\ Programa de Pós-Graduação em Estudos Linguísticos, Universidade Federal de Minas Gerais, \\ Belo Horizonte, MG, Brasil
}

Resumo: $O$ estudo da linguagem se insere em um ambiente no qual o texto impresso compartilha espaço com imagens, sons, vídeos e inúmeros recursos digitais. Essa realidade requer habilidades para lidar com leitura e escrita no papel de instrutor a ser desempenhado, com grande responsabilidade, pelo professor. Assim, reconhecendo a importância desse profissional no processo ensino-aprendizagem, o objetivo deste estudo é identificar competências digitais necessárias ao educador do século XXI. Para esse propósito, além dos conceitos de letramento e competência digital, foram abordadas diferentes perspectivas teórico-metodológicas, a saber: (a) o nível de proficiência dos professores pelo DigiCompEdu; e (b) a relação entre tecnologias digitais e práticas pedagógicas, por meio do TPACK, do Método SAMR e do Modelo de Competência Digital para Professores. A análise dos dados evidenciou uma série de competências que permitirão aos professores não somente lidar com as tecnologias digitais no exercício da docência, mas, também, auxiliar seus alunos a fazer uso crítico e criativo das TDIC.

Palavras-chave: Letramento digital; Proficiência digital; Formação profissional; TDIC.

Title: Digital proficiency of teachers: skills needed to teach in the $21^{\text {st }}$ century

Abstract: The language study is inserted in an environment in which the printed text shares space with images, sounds, videos, and countless digital resources. This reality requires skills to deal with reading and writing, while the teacher plays the role of instructor with great responsibility. Thus, recognizing the importance of this professional in the teachinglearning process, this study aims to identify the digital competences necessary for the $21^{\text {st }}$ century educator. For this purpose, in addition to the concepts of digital literacy and competence, different theoretical-methodological perspectives were approached, namely: (a) the proficiency level of teachers by the DigiCompEdu and (b) the relationship between digital technologies and pedagogical practices, with the TPACK, the SAMR method, and the digital competence model for teachers. The data analysis evidenced a series of competences that will allow teachers not only to deal with digital technologies while teaching, but also to help their students to critically and creatively use the digital information and communications technologies (DICT).

Keywords: Digital literacy; Digital proficiency; Vocational training; DICT.

\footnotetext{
${ }^{1}$ Doutorado em Linguística Aplicada, Instituto Federal de Educação, Ciência e Tecnologia do Espírito Santo. Orcid: http://orcid.org/0000-0001-6560-484X.

E-mail: josicani@gmail.com.
} 


\section{Introdução}

A plataforma digital We are social \& Hootsuite (KEMP, 2018), segundo o relatório Digital in 2018, apresenta dados de que mais da metade da população mundial está conectada digitalmente. $O$ estudo observa que o acesso à web ocorre por meio de seus principais veículos: dispositivos móveis (52\%); desktops e laptops (43\%); e tablets (4\%). 0 Brasil, conforme estatísticas demográficas e de consumo de internet, é o terceiro país do mundo que mais fica on-line, uma vez que seus cidadãos permanecem conectados, em média, 9h14min por dia, seja pelo computador, seja por dispositivos móveis, e, dentre os propósitos de conexão, $58 \%$ são usuários de redes sociais. A pesquisa destaca, também, que as pessoas ao redor do mundo estão cada vez mais perdendo o receio de comprar on-line e $45 \%$ da população já fez alguma transação comercial pela internet.

Esse cenário requer competências para lidar com o digital como requisito essencial para exercer papel de cidadão na sociedade. Isso porque, de acordo com o relatório Science, Technology and Innovation Outlook (OECD, 2018), o progresso tecnológico poderá acentuar as desigualdades econômicas e sociais, principalmente mediante a qualificação de mão de obra. Então, é preciso permitir à sociedade uma forma não somente de se beneficiar das inovações, mas também prepará-la para lidar com elas profissionalmente.

Assim, as Tecnologias Digitais de Informação e Comunicação (TDIC) evoluem, no século XXI, exigindo autonomia, pensamento crítico, capacidade de resolver problemas, inovação e aprendizagem permanente (DUDENEY; HOCKLY; PEGRUM, 2016). Nesse sentido, pesquisadores de diversas áreas já discutem a respeito do que o cidadão necessita para habilitá-lo a utilizar de forma competente e crítica os recursos tecnológicos digitais. Surgem, assim, estudos amplos e complexos, acompanhando a evolução digital, que refletem os objetivos sociais, econômicos, políticos, culturais e educacionais para uso de ferramentas digitais (FERRARI, 2012). Atendendo a esse cenário, investigações acadêmicas, documentos e relatórios descrevem habilidades e competências relacionadas às tecnologias digitais por meio de conceitos como: letramento digital (GILSTER, 1997; LANKSHEAR, 2006, 2008), multiletramentos (KALANTZIS; COPE; HARVEY, 2003; KALANTZIS; COPE, 2009), letramento computacional (FRAILLON et al., 2014; WARSCHAUER, 2011), habilidades da internet (VAN DEURSEN; VAN DIJK, 2011), novos letramentos (COIRO et al., 2014), letramento para as mídias digitais (BUCKINGHAM, 2010; JENKINS, 2007; LIVINGSTONE, 2014; POTTER, 2014) e competência digital (ALA-MUTKA, 2011; FERRARI, 2012; RØKENES; KRUMSVIK, 2014).

Embora esses conceitos estejam inseridos em ambientes educacionais, fizemos a escolha de trabalhar com os conceitos de letramento digital (BUZATO, 2006; BUCKINGHAM, 2010; GILSTER, 1997; SOARES, 2002) e de competência digital (ALA-MUTKA, 2011; FERRARI, 2012; INTEF, 2017; KRUMSVIK, 2011), por considerarmos os termos que mais se destacam em estudos da área educacional. Krumsvik (2011) evidencia que, mesmo que ocorra uma 
consolidação conceitual internacionalmente utilizada de letramento digital, há diferença de significados de uma forma holística adequada a particularidades dos dois conceitos.

É preciso, então, pensar em letramento/competência digital considerando fatores sociais, tecnológicos e econômicos (KRESS, 2003), sobretudo em uma sociedade imersa no digital em seus domínios de conhecimento, lazer, política, trabalho, consumo e participação social. Isso vai exigir da educação um papel e uma responsabilidade diferenciada, que atenda aos discursos presentes nessa demanda, principalmente nas relações de trabalho, uma vez que as novas ou reestruturadas profissões requerem formação digital e os que não estiverem aptos a isso estarão em desvantagem no mercado (EUROPE..., 2016).

Fundamental reflexão, então, é o reconhecimento de uma discussão em torno das competências para ensinar no século XXI, principalmente pela necessidade de novos letramentos emergentes de uma sociedade contemporânea. Assim, nosso objetivo é identificar competências digitais necessárias ao educador da atualidade. Procedemos com a análise de documentos, baseada em Puentedura (2006), Koehler e Mishra (2009), Krumsvik (2014) e Redecker (2017), com foco nos seguintes pontos em relação às TDIC: I) exploração: potencialidade de recursos em sala de aula; II) instrução: formas de trabalhar as ferramentas digitais; e III) integração: construção do conhecimento e integração com colegas de profissão e alunos.

\section{Desenvolvendo conceitos}

Dominar as múltiplas linguagens presentes na sociedade pode capacitar o ser humano a atribuir sentidos à vida pessoal, social e ao mundo do trabalho, muito além do "básico tradicional de leitura e de escrita da língua nacional" (KALANTZIS; COPE, 2009, p. 6). Nesse contexto, o desenvolvimento dos meios e das máquinas de produção da escrita proporcionou a "diluição da separação e das diferenças entre as diversas linguagens e letramentos" (ROJO; MOURA, 2019, p. 20), passando a combinar múltiplas linguagens, além da oral e da escrita. Assim, atendendo à necessidade de a escola se adequar aos novos letramentos emergentes da sociedade contemporânea, pela evolução das TDIC, principalmente com as mídias imagéticas e fônicas, surge a pedagogia dos multiletramentos. Em 1996, o New London Group, com um manifesto firmado por um grupo de pesquisadores dos letramentos, publicou $A$ pedagogy of multiliteracies: designing social futures (Uma pedagogia dos multiletramentos: desenhando futuros sociais) (ROJO, 2012).

Esse manifesto destaca dois pontos principais acerca dos multiletramentos: o primeiro é "a crescente multiplicidade e integração dos modos significativos de criação de significado, cujo texto também se relaciona ao visual, ao áudio, ao espacial, ao comportamento, e assim por diante", destacando as TDIC como recursos significativos para as novas estratégias de uso da linguagem; o segundo, justifica o termo multiletramentos "como uma forma de focar as realidades da crescente diversidade local e conectividade 
global" (NEW LONDON GROUP, 2006, p. 64). Nessa acepção, o termo multiletramentos permite maior espaço aos conceitos de mídia e de modalidade da língua, viabilizando e intensificando novas possibilidades de textos/discursos na sociedade (ROJO; MOURA, 2019).

\section{Letramento digital e competência digital}

A ideia de letramento se apresenta por variadas perspectivas, principalmente como direção política para alcançar a alfabetização. Essa provocação a respeito da aprendizagem de leitura e escrita tem se destacado nos estudos de diferentes autores (GILSTER, 1997; KATO, 1986; KLEIMAN, 1995; KRESS, 2003; MORTATTI, 2004; SOARES, 2011, 2014; STREET, 2003). Elucidando uma dessas abordagens, apresentamos Soares (2014, p. 66), para quem “o conceito de letramento envolve, portanto, sutilezas e complexidades difíceis de serem contempladas em uma única definição". Segundo a autora, quando o propósito é se ater à dimensão individual, o letramento é reconhecido como uma propriedade pessoal; entretanto, quando há um movimento para a dimensão social, ele passa a ser observado como um fenômeno cultural, ou seja, "um conjunto de atividades sociais que envolvem a língua escrita, e de exigências sociais de uso da língua escrita" (SOARES, 2014, p. 66-67).

Nessa circunstância, Soares (2002) desenvolve seu conceito de letramento, revestindo-o de contextos sociais que se propõem a novas práticas, adotando, então, as transformações nos modos de ler e escrever com o uso das tecnologias digitais. A autora ampliou o conceito de letramento para o de letramento digital como "um certo estado ou condição que adquirem os que se apropriam da nova tecnologia digital e exercem práticas de leitura e de escrita na tela, diferente do estado ou condição - do letramento - dos que exercem práticas de leitura e de escrita no papel".

Outras nomenclaturas foram dadas a esse vocábulo. Inicialmente foi cunhado o termo letramento visual, seguido de letramento tecnológico, letramento informacional e letramento digital (PEÑA-LÓPEZ, 2009; STOKES, 2002). Ainda que não tenha sido concebido por Paul Gilster, o debate do conceito iniciou-se com a publicação, por esse autor, do livro Digital literacy, em 1997 (BELSHAW, 2011, p. 83). Segundo Gilster, letramento digital é "a capacidade de compreender e utilizar informação em múltiplos formatos a partir de uma ampla variedade de fontes quando é apresentada por meio de computadores" (GILSTER, 1997, p. 1, tradução nossa). O pesquisador observa a importância do domínio de competências essenciais para o trabalho com o digital, não apenas as operacionais, mas, principalmente, o desenvolvimento do conhecimento, análise do conteúdo informativo, pesquisas na internet e navegação em hipertexto.

Ao longo das duas últimas décadas, o conceito de letramento digital foi incorporando outras ideias. Buzato (2006, p. 16) apresentou como conceito: 
conjuntos de letramentos (práticas sociais) que se apoiam, entrelaçam e apropriam mútua e continuamente por meio de dispositivos digitais para finalidades específicas, tanto em contextos socioculturais geograficamente e temporalmente limitados, quanto naqueles construídos pela interação mediada eletronicamente.

Assim, as práticas sociais avançam na compreensão de letramento digital a que se propõe Gilster (1997). Buckingham (2010) acrescenta a importância de, além das habilidades de localizar e selecionar material na web, a capacidade de avaliar e utilizar a pesquisa de forma crítica para transformar a informação em conhecimento. Coscarelli (2017) estende essa abordagem sobre estratégias necessárias para lidar com a navegação e habilidades de leitura, como localizar e avaliar, sintetizar, integrar e refletir sobre as informações encontradas.

Para Brydon (2011, p. 105, tradução nossa),

\begin{abstract}
o mundo contemporâneo exige habilidades avançadas de letramento. Estas incluem uma capacidade de pensamento crítico, incluindo contextualizar, analisar, adaptar e traduzir informações e interagir com os outros, dentro e além de sua comunidade de origem. O aumento do uso da internet está levando a uma chamada para multiletramentos ou letramentos digitais. Eles envolvem a capacidade de ler, escrever e interagir através de uma variedade de plataformas, ferramentas e meios, passando desde os sinais e a oralidade, a caligrafia, o impresso, a televisão, o rádio e o cinema até as redes sociais digitais e as mensagens de texto.
\end{abstract}

O letramento digital supõe, então, um conjunto de competências que se convergem a um componente digital (ALA-MUTKA, 2011). Os aspectos estão relacionados ao letramento na internet que, segundo Hofstetter (1998), apresenta relação com a segurança, conectividade, comunicação e desenvolvimento de páginas da web; ao letramento em TDIC, definido por Simonson et al. (1987, p. 233, tradução nossa) como "uma compreensão das características, capacidades e aplicações de computador, bem como a capacidade de implementar esse conhecimento no uso hábil e produtivo de aplicativos de computador adequados a papéis individuais na sociedade"; ao letramento midiático, capacidade de localizar e selecionar informações advindas das mídias, avaliando-as e utilizando-as de forma crítica (BUCKINGHAM, 2010); ao letramento informacional, que, de acordo com Gasque (2012, p. 28), "corresponde ao processo de desenvolvimento de competências para localizar, selecionar, acessar, organizar, usar informação e gerar conhecimento, visando à tomada de decisão e à resolução de problemas".

Portanto, de modo geral, o letramento digital corresponde a "competências de uso de dispositivos tecnológicos para localizar, selecionar, organizar, explorar, utilizar e produzir informações de forma crítica, ética e segura, visando à inserção do cidadão no mundo contemporâneo" (CANI, 2019). Nesse contexto, o domínio de linguagem, associado às TDIC, possibilitaria a todo cidadão se adequar às demandas da sociedade atual em esferas sociais, culturais, políticas e econômicas.

Outro conceito que estabelece relação entre educação, economia, política ou 
interesses sociais é o de competência digital. O Parlamento Europeu e a Comissão Europeia (EUROPEAN COMMISSION, 2013), no âmbito de suas estratégias para alcançar o letramento universal, apresentaram um quadro de referência com oito principais competências combinadas a aptidões, conhecimentos e atitudes essenciais ao desenvolvimento pessoal para o exercício da cidadania: (1) comunicação na língua materna; (2) comunicação em línguas estrangeiras; (3) competência matemática e competências básicas em ciências e tecnologia; (4) competência digital; (5) aprender a aprender; (6) competências sociais e cívicas; (7) espírito de iniciativa e espírito empresarial; e (8) sensibilidade e expressão culturais.

Ainda que consideradas igualmente importantes, a Comissão Europeia (EUROPE..., 2016) apontou como prioridade a competência digital, sendo condição essencial para inovação, crescimento econômico, progresso e, principalmente, exercício da cidadania. De acordo com a comissão, a compreensão ampla do conceito de competência digital refere-se à utilização segura e crítica da tecnologia para a comunicação, lazer e trabalho, sustentada por habilidades básicas e pelas TDIC: "o uso de computadores para recuperar, avaliar, armazenar, produzir, apresentar e trocar informações, e para se comunicar e participar de redes colaborativas através da Internet" (EUROPEAN COMMISSION, 2006, p. 15-16).

Ala-Mutka (2011) identifica a competência digital como uma competência-chave transversal, pois permite a aquisição de muitas outras competências, como a linguística, a matemática, a aprender a aprender e a consciência cultural, sendo essencial para a plena participação na atual sociedade. Esse conceito assinala que a competência é mais ampla e profunda que as habilidades, consistindo em atender a processos complexos e mobilizar recursos psicossociais (incluindo habilidades e atitudes) em contexto particular. 0 documento da OECD (2005) exemplifica essa questão, pontuando que para se comunicar de forma eficaz é necessária uma competência que abranja conhecimento da linguagem, habilidades práticas e atitudes em relação ao interlocutor, indo além de questões operacionais, que são uma pequena fração dos conhecimentos necessários para usar ferramentas digitais (FERRARI, 2012).

Em 2012, a definição de competência digital foi ampliada e aperfeiçoada por meio do projeto Competências Digitais para Professores (DigiComp), da Comissão Europeia, cujo objetivo foi compreender e melhor desenvolver a competência digital na Europa. Baseado nesse trabalho, Ferrari (2012, p. 3-4, tradução nossa) propôs a seguinte definição:

Competência digital é o conjunto de conhecimentos, habilidades, atitudes (incluindo habilidades, estratégias, valores e conscientização) que são necessários ao usar as TIC e mídia digital para realizar tarefas; resolver problemas; comunicar; gerenciar informações; colaborar; criar e compartilhar conteúdo; e construir conhecimento de forma eficaz, eficiente, apropriada, crítica, criativa, autônoma, flexível, ética e reflexiva para trabalho, lazer, participação, aprendizagem, socialização, consumo e empoderamento. 
Segundo o autor, grande parte dos frameworks de competência digital baseia-se no desenvolvimento de habilidades para usar um conjunto de ferramentas e/ou aplicativos. Porém, a definição acima destaca que as habilidades são apenas uma parte necessária aos domínios da aprendizagem inserida na competência digital para que um usuário possa lidar com um ambiente digital (FERRARI, 2012, p. 4). O autor propõe sete áreas adaptadas aos dias atuais para uso das tecnologias digitais: (1) gestão da informação; (2) colaboração; (3) comunicação e compartilhamento; (4) criação de conteúdo e conhecimento; (5) ética e responsabilidade; (6) avaliação e resolução de problemas; e (7) operações técnicas.

Outra proposta elaborada por organizações internacionais é a do Instituto Nacional de Tecnologías Educativas y de Formación del Profesorado (INTEF, 2017, p.9), que define competência digital como "o uso criativo, crítico e seguro das tecnologias de informação e comunicação para atingir os objetivos relacionados ao trabalho, empregabilidade, aprendizado, tempo livre, inclusão e participação na sociedade". O quadro proposto por essa organização espanhola apresenta cinco grandes áreas em três níveis (inicial, médio e avançado): (1) informação, (2) comunicação, (3) criação de conteúdo, (4) segurança e (5) resolução de problemas.

Identificamos, então, uma diversidade teórica a respeito dos termos "letramento digital" e "competência digital". Podemos concluir que, embora cada autor ou instituição enfatize diferentes aspectos, os dois termos caminham para uma direção multidimensional envolvendo processos cognitivos, técnicos, éticos, interacionais, conceituais, críticos, sociais, políticos e educacionais. Assim, nosso interesse se volta especificamente para a relação desses conceitos com a educação, que encoraje seus sujeitos a desenvolverem seus conhecimentos, com habilidade e autoconfiança, fazendo uso das tecnologias digitais, a fim de servi-los em suas necessidades diante das mudanças do século XXI.

Para o uso das tecnologias digitais, pela multiplicidade de significados e interpretações possíveis, tanto para letramento digital quanto para competência digital, é necessário formar cidadãos com habilidades básicas para navegar, se comunicar e se posicionar na internet. Como este estudo está centrado na docência, vamos ampliar, com base nas discussões anteriores, nosso conceito: o letramento digital corresponde à aquisição de habilidades, competências e atitudes voltadas ao uso das tecnologias digitais para localizar, selecionar, organizar, explorar, utilizar, produzir e compartilhar informações de forma crítica, ética, criativa, independente, reflexiva e segura para lazer, trabalho, socialização e aprendizagem, nas esferas educacionais, sociais, políticas, culturais ou econômicas, em diferentes formatos, gêneros e mídias, visando à inserção do cidadão no mundo contemporâneo por meio da educação.

Claro que se manter digitalmente letrado não é tarefa fácil para um cidadão, pois isso requer construir ou ampliar uma rede pessoal de aprendizagem de forma contínua. No cenário educacional, há uma dupla dimensão para o letramento digital dos professores, visto que, além de utilizarem as tecnologias digitais para fins pessoais (comunicação, transações comerciais, diversão etc.), eles necessitam fazer julgamentos didático-pedagógicos que 
permitam expandir os conhecimentos dos alunos (KRUMSVIK, 2011). Desse modo, em nossa próxima discussão abordamos os modos como os professores poderão se apropriar de meios para não somente participar de uma sociedade digital, mas também auxiliar seus alunos a fazerem uso crítico e criativo das tecnologias digitais.

\section{Caminhos metodológicos}

Este estudo, de cunho qualitativo, objetiva identificar competências digitais necessárias ao educador do século XXI. Assim, para descrever um conjunto de competências tecnológicas que poderá guiar os professores no processo de ensino-aprendizagem, seguimos um método de revisão de literatura (HART, 1998; JESSON; MATHESON; LACEY, 2011), apoiados nas seguintes etapas: (a) identificação de termos-chave para uso educacional das TDIC; (b) localização de teóricos e seus métodos de abordagem do tema; e (c) análise crítica da aplicabilidade dos estudos em ambientes de ensino.

Alguns termos de pesquisa foram identificados pela consulta à literatura no campo de uso das TDIC na formação de professores: "letramento digital + professor", "competência digital + professor", "alfabetização digital + professor" e "competência digital + ensino". Os bancos de dados mais importantes, no contexto educacional, utilizados na pesquisa foram Researchgate.net, Web of Science, Portal de Periódicos da Capes e Google Acadêmico. Assim sendo, como resultado os estudos incluídos se concentraram no DigCompEdu (REDECKER, 2017), no método SAMR (PUENTEDURA, 2006), pelo Modelo TPACK (KOEHLER; MISHRA, 2009) e pelo Modelo de Competência Digital para Professores (KRUMSVIK, 2014).

\section{Conhecimento tecnológico digital dos professores}

O conceito de competência profissional pode ser definido como o conjunto de habilidades, conhecimentos, atitudes e variáveis motivacionais que estruturam a base para o domínio de situações específicas (KLIEME; HARTIG; RAUCH, 2008). A competência dos professores se destaca no currículo nacional brasileiro, por meio da Base Nacional Comum Curricular (BNCC), como "mobilização de conhecimentos (conceitos e procedimentos), habilidades (práticas cognitivas e socioemocionais), atitudes e valores para resolver demandas complexas da vida cotidiana, do pleno exercício da cidadania e do mundo do trabalho" (BRASIL, 2018, p. 8). Ainda nesse documento, há a referência de que são imprescindíveis a compreensão e a incorporação da escola às novas linguagens do universo digital e seus modos de funcionamento.

Assim, o uso das TDIC torna-se cada vez mais importante no trabalho dos professores (KRUMSVIK, 2011), principalmente para o desenvolvimento e o progresso de forma global por uma sociedade baseada na informação (CASTELLS, 2001). Apresentamos, a seguir, as 
orientações político-pedagógicas que poderão auxiliar os professores em sua formação com o uso das TDIC.

Proficiência digital dos professores: o DigCompEdu

As TDIC contribuem com o ensino não simplesmente por viabilizar a entrega de conteúdos, mas também por sua capacidade de atuar como apoio ao esforço dos alunos para alcançar sua aprendizagem (TAMIM et al., 2011). Como resposta à crescente conscientização de formação em competências digitais para melhoria e inovação do ensino, a Comissão Europeia (2016) desenvolveu o Quadro Europeu de Competência Digital para Educadores (Framework DigCompEdu) (REDECKER, 2017). Segundo esse documento, a competência digital é reconhecida como transversal para a aquisição de outras competências para aprendizagem ao longo da vida, como a comunicação em língua materna e línguas estrangeiras e competência em Matemática e Ciências.

A inserção do cidadão na sociedade digital tem demandado mudanças em muitos segmentos que exigem a presença das TDIC no trabalho, na educação, na política e no social. Dentre muitos quadros sobre capacitação para a transformação digital, ${ }^{2}$ o DigCompEdu apresenta uma estrutura de base cientificamente sólida, orientando políticas de formação de professores com a implementação de ferramentas e de programas de treinamento regionais e nacionais. A proposta engloba educadores de todos os níveis de ensino, da infância à educação superior e de adultos, incluindo necessidades especiais e contextos de aprendizagem formal.

O DigCompEdu (REDECKER, 2017) considera, dentro de 23 competências, seis áreas necessárias aos educadores para a aquisição de estratégias de aprendizagem eficazes, abrangentes e inovadoras, usando ferramentas digitais: (1) engajamento profissional; (2) recursos digitais; (3) ensino e aprendizagem; (4) avaliação; (5) empoderamento dos alunos; e (6) promoção da competência digital dos estudantes. Para cada uma delas são apresentados descritores de função que se refletem no modo como cada um utiliza as tecnologias dentro de uma comunidade profissional para aprimorar e inovar a educação, explicitados na Figura 1.

\footnotetext{
${ }^{2}$ Cf. DigCompOrg - quadro para organizações educacionais; DigCompConsumers - quadro para consumidores; OpenEdu - Instituições de Ensino Superior (EUROPE..., 2016).
} 
Figura 1 - Estrutura de níveis de proficiência do DigCompEdu

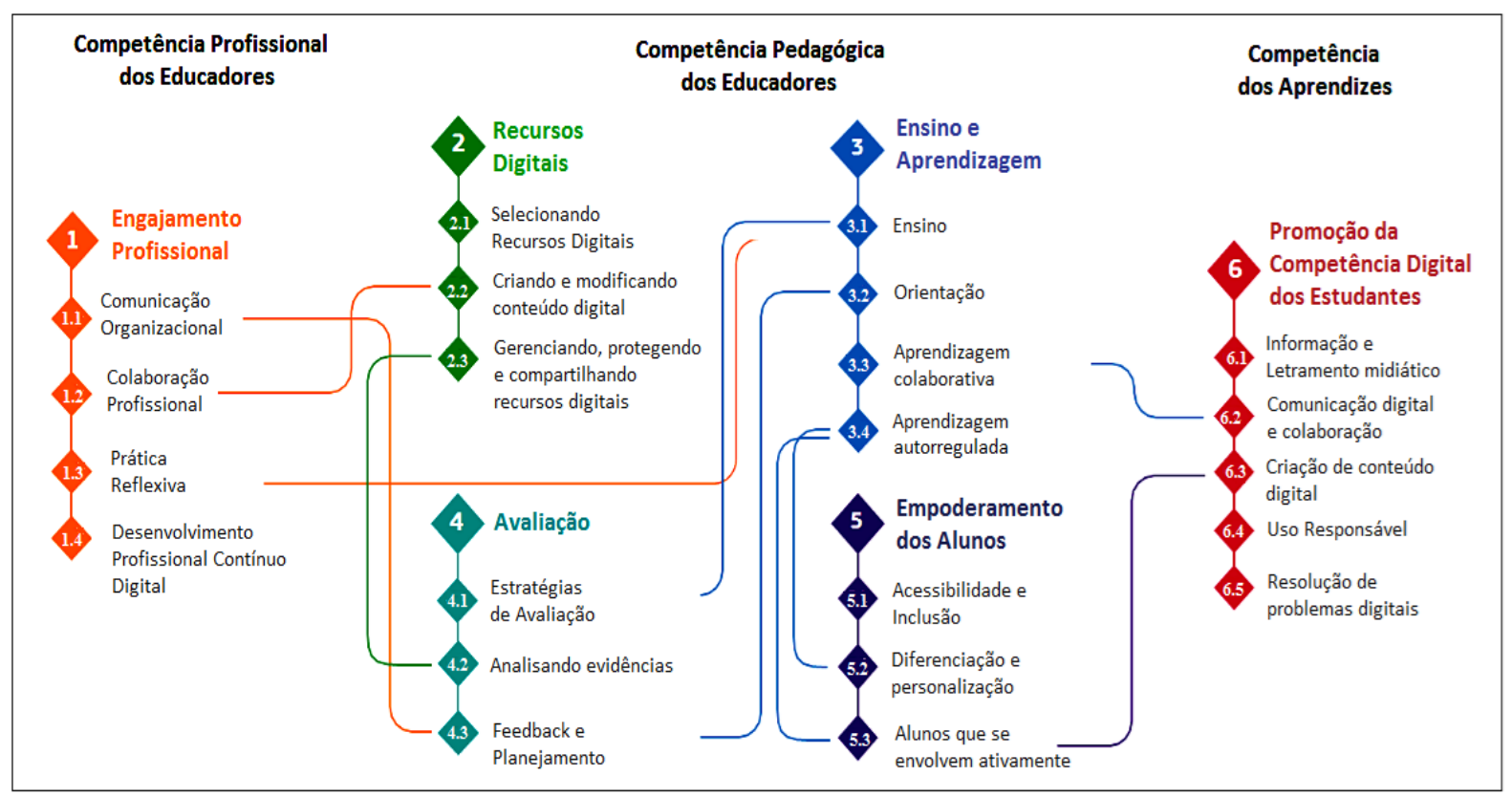

Fonte: Redecker (2017, p. 8, tradução nossa).

Um dos principais pontos fortes das TDIC na educação, segundo o DigCompEdu (REDECKER, 2017), é o seu potencial para apoiar as práticas pedagógicas dos professores centradas nos alunos, isto é, estratégias que impulsionem envolvimento ativo desses sujeitos no processo de ensino-aprendizagem. Nesse contexto, as tecnologias digitais poderão ser usadas para experiências criadas sob reflexões e tomadas de decisões dos educandos em busca de soluções de problemas. Assim, além de colaborar com uma sala de aula e uma educação mais personalizada, as TDIC poderão contribuir com atividades adaptadas ao nível de competência, necessidades e interesses de aprendizagem de cada aluno.

Para incentivar os professores a fazerem uso do DigCompEdu como uma proposta para seu desenvolvimento profissional, foram estabelecidos níveis de proficiência que os motivassem a perceber suas conquistas e os incitassem a expandir seus conhecimentos digitais. O site da Comissão Europeia, JRC Science Hub Communities, lançou uma consulta especializada sobre uma primeira ferramenta de avaliação ${ }^{3}$ do DigCompEdu. Essa ferramenta permite que o professor reflita sobre sua competência digital, identificando seus pontos fortes e fracos, além das áreas que permitirão a eles avanços em suas práticas pedagógicas com o uso das TDIC para ensino-aprendizagem. São 22 questões de autoavaliação; após o envio, o usuário recebe um feedback detalhado com dicas e sugestões das principais etapas para inovar o ensino. O site direciona os professores conforme seu segmento de atuação, educação básica, ensino superior e educação de adultos, com questões que abordam as seis áreas apontadas anteriormente.

\footnotetext{
${ }^{3}$ Disponível em: https://ec.europa.eu/eusurvey/runner/DigCompEdu-S-PT. Acesso em: 24 jan. 2019.
} 
Inspirado na taxonomia de Bloom ${ }^{4}$ (ANDERSON; KRATHWOHL, 2001), o modelo que segue identifica fases subsequentes de aprendizagem cognitiva dos educadores, intencionando não uma classificação estática, mas uma motivação para que cada um expanda seus conhecimentos a respeito das potencialidades das TDIC. São elas: A1: recémchegado; A2: explorador; B1: integrador; B2: especialista; C1: líder; e C2: pioneiro.

Figura 2 - Modelo de progressão de professores

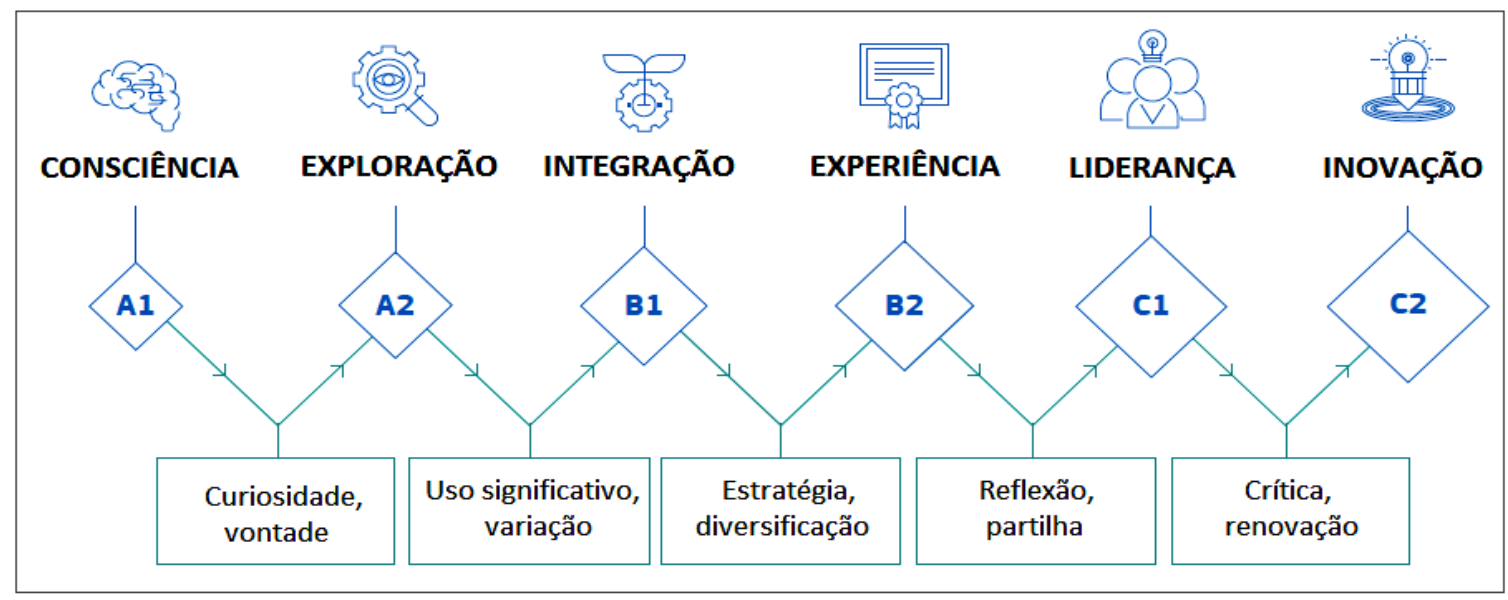

Fonte: Redecker (2017, p. 29, tradução nossa).

Essa taxonomia apresenta os estágios cognitivos subsequentes de qualquer progresso de aprendizado: lembrar, entender, aplicar, analisar, avaliar e criar. Nessa mesma perspectiva, as duas primeiras etapas do DigCompEdu, A1: recém-chegado e A2: explorador, identificam que os educadores assimilam novas informações e desenvolvem práticas digitais básicas; nos dois estágios seguintes, B1: integrador e B2: especialista, os educadores aplicam, expandem e refletem sobre suas práticas digitais; nas fases mais altas, C1: líder e C2: pioneiro, os educadores transmitem seus conhecimentos, criticam a prática existente e desenvolvem novas práticas (REDECKER, 2017). Reafirmamos que essas características não são estáticas, pois permitem que um professor transite por perfis diferentes, ou seja, um professor que se enquadre majoritariamente em um nível de proficiência pode apresentar habilidades assinaladas em outro quadro.

Vamos, então, apresentar os níveis propostos pelo DigCompEdu que poderão ser aplicados aos professores (REDECKER, 2017). Para todas as competências, a progressão dos níveis de proficiência é cumulativa, o que acarreta a inserção dos níveis inferiores em cada descritor de nível mais alto, com exceção do primeiro nível (A1: recém-chegado).

\footnotetext{
${ }^{4}$ Estrutura de organização hierárquica cujo objetivo é auxiliar no planejamento, organização e controle das metas de aprendizagem.
} 
Quadro 1 - Níveis de proficiência digital dos professores - A1: recém-chegado

\section{A1: Recém-chegado}

Embora ciente do potencial das TDIC para melhorar sua prática pedagógica, teve pouco contato com tais recursos, necessitando de orientação e incentivo para expandir seu repertório e aplicar sua competência digital existente no campo pedagógico.

\begin{tabular}{|l|l|}
\hline $\begin{array}{l}\text { 1. Engajamento } \\
\text { profissional }\end{array}$ & $\begin{array}{l}\text { - Faz pouco uso de TDIC para comunicação, colaboração entre pares e atualização } \\
\text { de conhecimentos. } \\
\text { - Não sabe como melhorar suas habilidades digitais. }\end{array}$ \\
\hline 2. Recursos digitais & $\begin{array}{l}\text { - Faz pouco uso da internet para encontrar e compartilhar recursos. } \\
\text { - Abstém-se de modificar recursos digitais. }\end{array}$ \\
\hline $\begin{array}{l}\text { 3. Ensino e } \\
\text { aprendizagem }\end{array}$ & $\begin{array}{l}\text { - Faz pouco uso de TDIC para instrução, interação com alunos, atividades de } \\
\text { aprendizagem colaborativa e autorregulada. }\end{array}$ \\
\hline 4. Avaliação & $\begin{array}{l}\text { - Faz pouco uso de TDIC para avaliação e monitoramento do progresso dos alunos, } \\
\text { assim como para dar feedback da situação escolar. }\end{array}$ \\
\hline $\begin{array}{l}\text { 5. Empoderamento } \\
\text { dos alunos }\end{array}$ & $\begin{array}{l}\text { - Preocupa-se com acessibilidade e inclusão, mas não reconhece o potencial das } \\
\text { TDIC para diferenciação e personalização. } \\
\text { - Faz pouco uso de TDIC para envolver o aluno. }\end{array}$ \\
\hline $\begin{array}{l}\text { 6. Promoção da } \\
\text { competência digital } \\
\text { dos alunos }\end{array}$ & $\begin{array}{l}\text { - Faz pouco uso de estratégias que promovam a alfabetização informacional e a } \\
\text { comunicação digital dos alunos. } \\
\text { - Não promove a criação de conteúdo digital pelos alunos nem a resolução de } \\
\text { problemas. }\end{array}$ \\
\hline
\end{tabular}

Fonte: Adaptado de Redecker (2017).

Quadro 2 - Níveis de proficiência digital dos professores - A2: explorador

\section{A2: Explorador}

Ciente do potencial das TDIC, possui interesse em explorá-las para melhorar sua prática pedagógica. Embora utilize as tecnologias digitais em algumas áreas, não segue uma abordagem muito consistente. Necessita de encorajamento, percepção e inspiração por meio de exemplos ou orientações de pares mais experientes em um intercâmbio colaborativo.

\begin{tabular}{|l|l|}
\hline $\begin{array}{l}\text { 1. Engajamento } \\
\text { profissional }\end{array}$ & $\begin{array}{l}\text { - Está ciente das TDIC e faz uso básico para comunicação e colaboração. } \\
\text { - Usa a internet para atualizar o conhecimento. }\end{array}$ \\
\hline 2. Recursos digitais & $\begin{array}{l}\text { - Faz uso básico de TDIC para encontrar recursos, além de criar e modificar alguns } \\
\text { recursos com estratégias básicas. }\end{array}$ \\
\hline $\begin{array}{l}\text { 3. Ensino e } \\
\text { aprendizagem }\end{array}$ & $\begin{array}{l}\text { - Faz uso básico de TDIC disponíveis para instrução e interação com os alunos. } \\
\text { - Incentiva os alunos a usar TDIC em suas atividades colaborativas e atividades de } \\
\text { aprendizado autorregulado. }\end{array}$ \\
\hline 4. Avaliação & $\begin{array}{l}\text { - Integra TDIC em estratégias tradicionais de avaliação. } \\
\text { - Avalia dados básicos sobre atividade e desempenho do aluno com feedback. }\end{array}$ \\
\hline $\begin{array}{l}\text { 5. Empoderamento } \\
\text { dos alunos }\end{array}$ & $\begin{array}{l}\text { - Preocupa-se com acessibilidade e inclusão, mas não reconhece o potencial das } \\
\text { TDIC para diferenciação e personalização. } \\
\text { - Usa TDIC para o envolvimento do aluno. }\end{array}$ \\
\hline $\begin{array}{l}\text { 6. Promoção da } \\
\text { competência digital } \\
\text { dos alunos }\end{array}$ & $\begin{array}{l}\text { - Incentiva os alunos a usarem TDIC para recuperação informacional, comunicação, } \\
\text { colaboração, criação de conteúdo, resolução de problemas, utilizando-as de forma } \\
\text { segura e responsável. }\end{array}$ \\
\hline
\end{tabular}
Fonte: Adaptado de Redecker (2017).

Quadro 3 - Níveis de proficiência digital dos professores - B1: integrador

\section{B1: Integrador}

Experimenta as TDIC em variados contextos e propósitos, integrando-as criticamente em suas práticas profissionais. Anseia expandir seus conhecimentos tecnológicos; no entanto, ainda necessita entender 
melhor as affordances das ferramentas digitais. Necessita de um tempo maior de experimentação e reflexão de forma colaborativa e troca de conhecimento para se tornar especialista.

\begin{tabular}{|l|l|}
\hline $\begin{array}{l}\text { 1. Engajamento } \\
\text { profissional }\end{array}$ & $\begin{array}{l}\text { - Usa TDIC para comunicação de maneira efetiva e responsável, compartilhando e } \\
\text { trocando práticas. } \\
\text { - Usa experimentação e aprendizagem entre pares como fonte de desenvolvimento, } \\
\text { identificando oportunidades de desenvolvimento profissional contínuo. }\end{array}$ \\
\hline 2. Recursos digitais & $\begin{array}{l}\text { - Identifica e avalia recursos adequados usando critérios básicos. } \\
\text { - Cria e modifica recursos usando alguns recursos avançados. } \\
\text { - Compartilha e protege efetivamente os recursos usando estratégias básicas. }\end{array}$ \\
\hline $\begin{array}{l}\text { 3. Ensino e } \\
\text { aprendizagem }\end{array}$ & $\begin{array}{l}\text { - Integra as TDIC disponíveis de maneira significativa no processo de ensino, } \\
\text { melhorando a interação com os alunos. }\end{array}$ \\
\hline 4. Avaliação & $\begin{array}{l}\text { - Emprega e modifica ferramentas e formatos de avaliação digital existentes. } \\
\text { - Avalia e usa uma gama de dados digitais para informar o ensino, fornecendo } \\
\text { feedback. }\end{array}$ \\
\hline $\begin{array}{l}\text { 5. Empoderamento } \\
\text { dos alunos }\end{array}$ & $\begin{array}{l}\text { - Preocupa-se com acessibilidade e inclusão e utiliza o potencial das TDIC para } \\
\text { diferenciação e personalização. } \\
\text { - Promove o uso ativo de TDIC pelos alunos. }\end{array}$ \\
\hline $\begin{array}{l}\text { 6. Promoção da } \\
\text { competência digital } \\
\text { dos alunos }\end{array}$ & $\begin{array}{l}\text { - Implementa atividades que promovam a informação dos alunos, o letramento } \\
\text { midiático, a comunicação digital e a colaboração entre eles. } \\
\text { - Promove a criação de conteúdo digital pelos alunos, bem como a resolução de } \\
\text { problemas. }\end{array}$ \\
\hline
\end{tabular}

Fonte: Adaptado de Redecker (2017).

\section{Quadro 4- Níveis de proficiência digital dos professores - B2: especialista}

\section{B2: Especialista}

Utiliza variedades de TDIC com confiança, criatividade e criticidade para aprimorar suas práticas pedagógicas. Além de selecionar tecnologias digitais para propósitos particulares, percebe os benefícios e as desvantagens em seus usos. Aberto a novas ideias, reconhece que ainda há muitas experiências a serem vividas por meio das tecnologias digitais.

\begin{tabular}{|l|l|}
\hline $\begin{array}{l}\text { 1. Engajamento } \\
\text { profissional }\end{array}$ & $\begin{array}{l}\text { - Usa TDIC de forma estruturada e responsiva para construir conhecimento } \\
\text { colaborativo. } \\
\text { - Usa inúmeros recursos para desenvolver práticas digitais pedagógicas. } \\
\text { - Explora oportunidades on-line para o desenvolvimento profissional contínuo. }\end{array}$ \\
\hline 2. Recursos digitais & $\begin{array}{l}\text { - Identifica e avalia recursos adequados usando critérios complexos. } \\
\text { - Adapta recursos digitais avançados a um contexto concreto de aprendizagem. } \\
\text { - Compartilha recursos profissionalmente. }\end{array}$ \\
\hline $\begin{array}{l}\text { 3. Ensino e } \\
\text { aprendizagem }\end{array}$ & $\begin{array}{l}\text { - Usa TDIC propositadamente para melhorar estratégias pedagógicas, } \\
\text { monitoramento, orientação, aprendizagem colaborativa e autorregulada. }\end{array}$ \\
\hline 4. Avaliação & $\begin{array}{l}\text { - Estrategicamente usa uma variedade de formatos de avaliação digital. } \\
\text { - Emprega estrategicamente ferramenta digital para geração de dados. } \\
\text { - Usa dados digitais para melhorar a eficácia do feedback e suporte. }\end{array}$ \\
\hline $\begin{array}{l}\text { 5. Empoderamento } \\
\text { dos alunos }\end{array}$ & $\begin{array}{l}\text { - Promove uso de TDIC, permitindo acessibilidade e inclusão. } \\
\text { - Estrategicamente usa uma gama de TDIC para diferenciação e personalização e } \\
\text { engajamento ativo dos alunos com o assunto. }\end{array}$ \\
\hline $\begin{array}{l}\text { 6. Promoção da } \\
\text { competência digital } \\
\text { dos alunos }\end{array}$ & $\begin{array}{l}\text { - Utiliza estrategicamente estratégias pedagógicas para promover a informação, o } \\
\text { letramento midiático, a comunicação e a colaboração digital dos alunos. } \\
\text { - Usa uma gama de estratégias pedagógicas para promover a criação de conteúdo } \\
\text { digital pelos alunos e a promoção de resolução de problemas digitais. }\end{array}$ \\
\hline
\end{tabular}
Fonte: Adaptado de Redecker (2017). 
Quadro 5- Níveis de proficiência digital dos professores - C1: líder

\begin{tabular}{|c|c|}
\hline \multicolumn{2}{|r|}{ C1: Líder } \\
\hline \multicolumn{2}{|c|}{$\begin{array}{l}\text { Apresenta uma abordagem consistente e abrangente para o uso das TDIC em suas práticas pedagógicas e, } \\
\text { contando com um repertório de estratégias digitais, escolhe as mais adequadas para qualquer situação. } \\
\text { Reflete continuamente sobre suas práticas e se mantém atualizado, servindo como fonte de inspiração para } \\
\text { outros pares. }\end{array}$} \\
\hline $\begin{array}{l}\text { 1. Engajamento } \\
\text { profissional }\end{array}$ & $\begin{array}{l}\text { - Avalia e discute estratégias de comunicação. } \\
\text { - Usa TDIC para refletir e aprimorar práticas e competências. } \\
\text { - Reflete colaborativamente, aprimorando a prática pedagógica em geral. } \\
\text { - Usa a internet para o desenvolvimento profissional contínuo. }\end{array}$ \\
\hline 2. Recursos digitais & $\begin{array}{l}\text { - Identifica e avalia de forma abrangente os recursos adequados, considerando } \\
\text { todos os aspectos relevantes para criar, cocriar e modificar recursos de acordo com } \\
\text { o contexto de aprendizagem, usando uma gama de estratégias avançadas. } \\
\text { - Publica recursos digitais criados por ele mesmo. }\end{array}$ \\
\hline $\begin{array}{l}\text { 3. Ensino e } \\
\text { aprendizagem }\end{array}$ & $\begin{array}{l}\text { - Orquestra, monitora e adapta de forma flexível o uso de TDIC para melhorar as } \\
\text { estratégias pedagógicas. } \\
\text { - Usa ambientes digitais para geração de conhecimento colaborativo de alunos, } \\
\text { aprendizagem autorregulada e avaliação de colegas. }\end{array}$ \\
\hline 4. Avaliação & $\begin{array}{l}\text { - Seleciona, de forma abrangente e crítica, formatos de avaliação digital. } \\
\text { - Usa meio digital para refletir sobre aprendizagem e estratégias de ensino. } \\
\text { - Usa TDIC para personalizar feedback e suporte. }\end{array}$ \\
\hline $\begin{array}{l}\text { 5. Empoderamento } \\
\text { dos alunos }\end{array}$ & $\begin{array}{l}\text { - Melhora a acessibilidade e a inclusão, implementando de forma abrangente e } \\
\text { crítica a aprendizagem diferenciada e personalizada. } \\
\text { - Implementa estratégias para a aprendizagem ativa. }\end{array}$ \\
\hline $\begin{array}{l}\text { 6. Promoção da } \\
\text { competência digital } \\
\text { dos alunos }\end{array}$ & $\begin{array}{l}\text { - Promove de forma abrangente e crítica a informação e o letramento midiático. } \\
\text { - Promove de forma abrangente e crítica a comunicação digital, a colaboração, a } \\
\text { criação de conteúdo digital e resolução de problemas pelos alunos. } \\
\text { - Desenvolve de forma estratégica e crítica o uso responsável e seguro das TDIC } \\
\text { pelos alunos. }\end{array}$ \\
\hline
\end{tabular}

Fonte: Adaptado de Redecker (2017).

Quadro 6 - Níveis de proficiência digital dos professores - C2: pioneiro

\section{C2: Pioneiro}

Questiona a adequação de práticas digitais e pedagógicas contemporâneas, preocupado com as limitações ou desvantagens dessas práticas impulsionadas pela intenção de inovar a educação. Experimenta TDIC altamente inovadoras e complexas e/ou desenvolve novas abordagens pedagógicas, sendo exemplo para jovens professores.

\begin{tabular}{|l|l|}
\hline $\begin{array}{l}\text { 1. Engajamento } \\
\text { profissional }\end{array}$ & $\begin{array}{l}\text { - Reflete e redesenha estratégias de comunicação. } \\
\text { - Usa TDIC para inovar políticas e práticas educacionais. } \\
\text { - Usa a internet para fornecer desenvolvimento profissional contínuo aos pares. }\end{array}$ \\
\hline 2. Recursos digitais & $\begin{array}{l}\text { - Promove o uso de recursos digitais na educação. } \\
\text { - Cria recursos digitais complexos e interativos. } \\
\text { - Publica, profissionalmente, conteúdo digital autocriado. }\end{array}$ \\
\hline $\begin{array}{l}\text { - Usa TDIC para inovar estratégias de ensino, assim como para orientação e } \\
\text { aprendizagem }\end{array}$ & $\begin{array}{l}\text { colaboração do aluno. } \\
\text { - Desenvolve novos formatos digitais e/ou abordagens pedagógicas para } \\
\text { aprendizagem autorregulada. }\end{array}$ \\
\hline 4. Avaliação & $\begin{array}{l}\text { - Desenvolve formatos inovadores de avaliação com TDIC, inovando na geração e } \\
\text { avaliação de dados. } \\
\text { - Usa dados digitais para avaliar e melhorar o ensino. }\end{array}$ \\
\hline $\begin{array}{l}\text { 5. Empoderamento } \\
\text { dos alunos }\end{array}$ & $\begin{array}{l}\text { - Inova em estratégias de acessibilidade e inclusão, implementando de forma } \\
\text { abrangente e crítica a aprendizagem diferenciada e personalizada. } \\
\text { - Inova estratégias digitais para a aprendizagem ativa. }\end{array}$ \\
\hline 6. Promoção da & - Utiliza formatos inovadores para fomentar a informação e o letramento \\
\hline
\end{tabular}


competência digital dos alunos midiático, para promover a comunicação digital e a colaboração dos alunos.

- Usa formatos inovadores para fomentar nos alunos a criação de conteúdo digital.

- Desenvolve abordagens inovadoras para promover a capacidade dos alunos de usar TDIC para seu próprio bem-estar, assim como a resolução de problemas digitais dos alunos.

O principal objetivo desse modelo proposto pelo DigCompEdu (REDECKER, 2017) é oferecer suporte para o desenvolvimento profissional contínuo dos educadores. 0 documento deixa claro que não é um quadro normativo ou qualquer tipo de proposta classificatória, mas um indicativo destinado a auxiliar os professores a entenderem suas forças e fraquezas pessoais, descrevendo diferentes estágios nos quais eles possam perceber em que situação se encontram, o que já conseguiram alcançar e quais os próximos passos para desenvolverem uma proficiência em tecnologias digitais nas escolas.

Ramos (2016) destaca que ainda existem lacunas de cunho teórico e prático relacionadas ao mapeamento e descrição de competências e níveis de letramento digital para a formação de professores. Assim, o modelo proposto pelo DigCompEdu poderá contribuir não só para reduzir tais lacunas, como também oferecer um material a novos estudos sobre a proficiência desses profissionais para uso das tecnologias digitais.

Do conhecimento técnico ao conhecimento pedagógico: SAMR, TPACK e o Modelo de Competência Digital para Professores

A materialização das TDIC em um currículo educativo implica a oportunidade de construir saberes tecnológicos e pedagógicos, o que é bastante diferente de usar tecnologias digitais para fins de entretenimento, como as redes sociais. Haugerud (2011) observa que a integralização ou combinação de uma proficiência técnica isolada não é suficiente para proporcionar oportunidades de ensino. Assim, parece "haver uma lacuna entre conhecimento técnico e conhecimento sobre como empregar tecnologia em um contexto de aprendizagem. Sob essa luz, os professores-alunos precisam desenvolver uma visão sobre as TIC que vá além dos meros aspectos técnicos" (HAUGERUD, 2011, p. 227, tradução nossa).

Faz-se necessária, então, uma relação interligada, dentro das salas de aula, entre professor e produção do conhecimento. A respeito da aplicação das TDIC pelos professores em suas práticas pedagógicas, Puentedura (2006) apresenta um modelo em quatro níveis, explicitados a seguir: 
Figura 3 - Estrutura do modelo SAMR

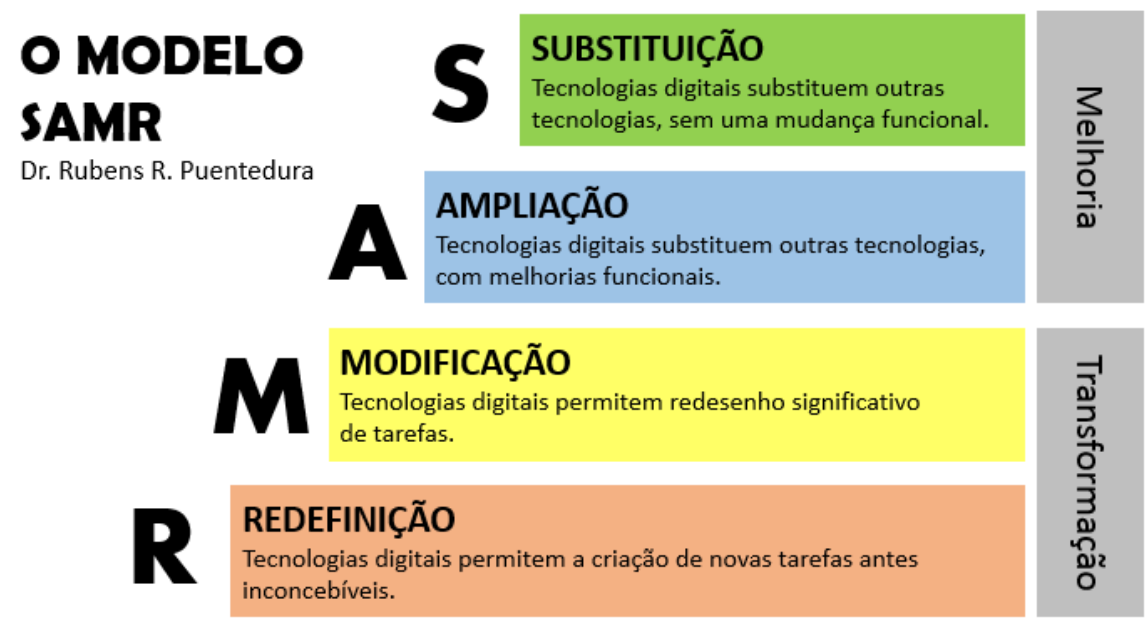

Fonte: Puentedura (2006, p. 2, tradução nossa).

Para o autor, leitura em meios digitais, uso de editores de textos e apresentação de slides configuram substituição (S) de uma tecnologia por outra sem mudanças significativas para o processo de ensino-aprendizagem. Essas ferramentas servem aos mesmos propósitos de suas contrapartes analógicas (livros impressos, escrita e aula oral), sem transformar a natureza do ensino (CYSNEIROS, 1998). Um exemplo disso é a consulta a um dicionário online em vez de um material impresso, ambos com o mesmo conteúdo. Claro que não podemos nos esquivar da facilidade, pois há sites de busca que oferecem o significado apenas digitando a palavra, mas mesmo assim não modificam o propósito de aprendizagem.

A integração de outras fontes e mídias ao meio digital, como o acesso a diferentes conteúdos de um conhecimento histórico, poderia ser classificada como ampliação (A), mesmo que ainda se configure em abordagens características do modelo tradicional. Esse processo permite aos alunos ampliar seus conhecimentos de forma mais independente, compartilhando assuntos de seus interesses, conhecimentos e até questionamentos com a expansão de diferentes ferramentas tecnológicas (LUCENA, 2016). Esses dois níveis, S e A, dão início à inserção das tecnologias digitais no processo educacional, sendo identificados como melhoria do ensino por meio das TDIC.

Segundo Puentedura (2006), é na modificação (M) que começam os processos de autoria e compartilhamento dos recursos educativos. Esse processo pressupõe a transformação dos procedimentos educacionais nos quais o educador, valendo-se das possibilidades oferecidas pela internet, incentiva o aluno a produzir e a publicar conteúdos na rede, construindo conhecimento. Inicia-se, a partir daí, o protagonismo do aluno na edificação de seus saberes sem a postura única de consumidor do virtual.

Quanto às tarefas de redefinição $(R)$, as atividades extrapolam o que se realiza em $M$ para um processo mais colaborativo de construção em rede, por meio do qual os alunos passam a participar de grupos com contribuições e compartilhamento de suas produções. As estratégias tradicionais de interação dos estudantes são transformadas por recursos digitais 
que redefinem o ensino: enquanto estudantes de medicina aperfeiçoam suas habilidades cirúrgicas em operações virtuais, atletas estudam possibilidades para melhorar seu desempenho em jogos e outras competições em simulações digitais. Assim, a aprendizagem é o resultado, enquanto a tecnologia é a ferramenta para alcançar um propósito. Esses dois níveis, $M$ e R, passam, então, a significar a transformação de práticas educacionais pelo uso das TDIC.

Modelos como o de Puentedura (2006) continuam a surgir de diferentes relatórios, pesquisas e documentos que se dedicam a identificar possíveis estratégias formativas que permitam aos docentes acompanhar a evolução digital. Outra proposta teórica sobre tecnologias digitais e formação de professores foi criada por Krumsvik (2007, 2011, 2014): o Modelo de Competência Digital para Professores. Segundo o autor, é necessário estabelecer um arcabouço pedagógico e um conteúdo didático relacionado às práticas dos professores se a intenção for incorporar a competência digital a escolas digitalizadas e à formação de professores.

Figura 4 - Modelo de Competência Digital para Professores

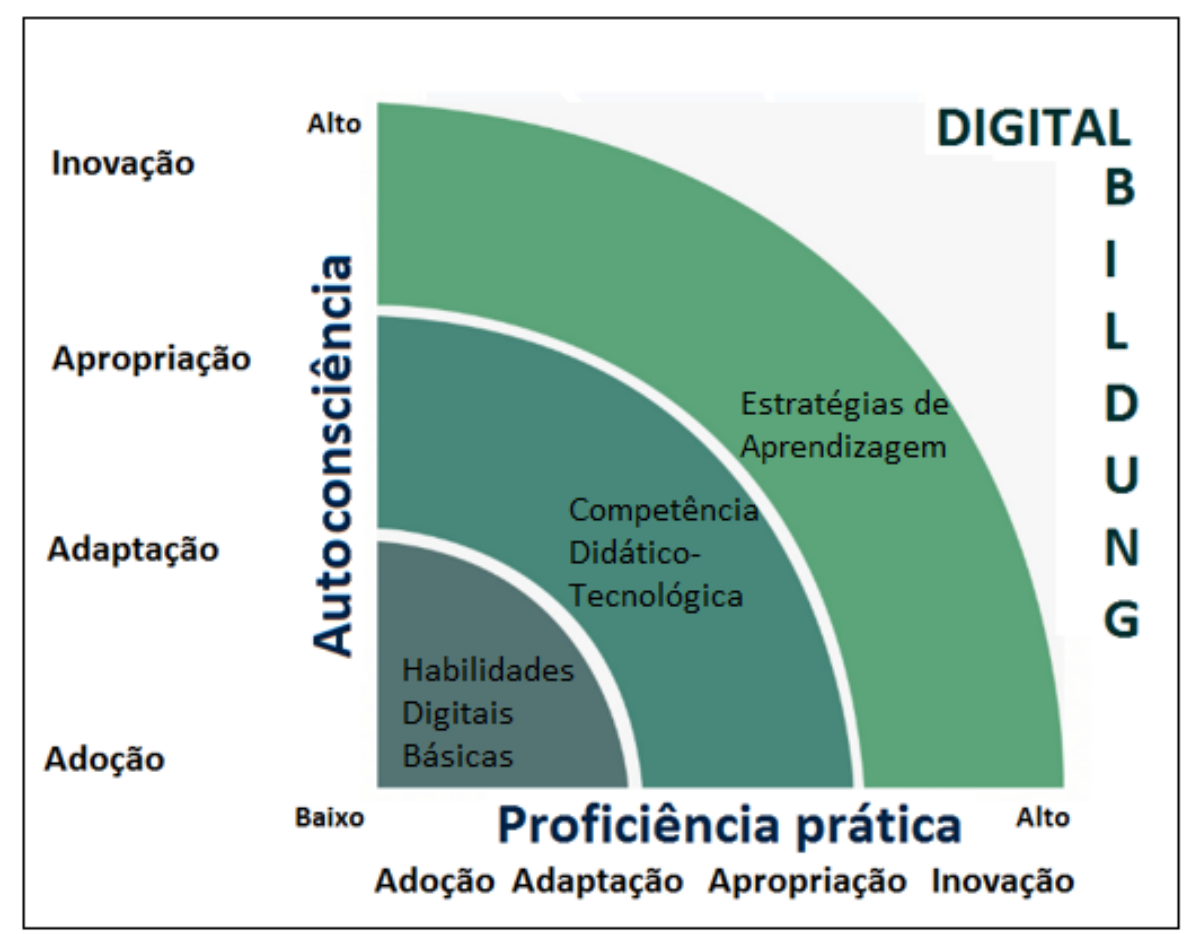

Fonte: Traduzido por Silva (2016, p. 131) a partir de Krumsvik (2011, p. 45).

Krumsvik (2011) observa que estruturas, definições e descrições carecem de funcionalidade na prática, inclusive por meio de ações que sejam operacionalizadas em um contexto de ensino no qual documentos de políticas públicas também levem isso em consideração. O modelo evidencia quatro componentes principais em uma teia complexa de práticas para além das habilidades técnicas que, se a princípio são autoconscientes, acabam 
se tornando "invisíveis" quando passam a ser internalizadas: (1) habilidades digitais básicas; (2) competência didático-tecnológica; (3) estratégias de aprendizagem; e (4) formação digital (SILVA, 2016). O primeiro componente indica que as ferramentas devem ser "transparentes" para que o professor possa entender seus usos, ou seja, as tecnologias precisam ser amigáveis e utilizadas em sua vida diária, como uso do computador para acessar e-mail, internet banking etc. O segundo componente, competência didático-pedagógica, está relacionado à teoria e à dialética da prática para o uso das tecnologias na educação, ou seja, à capacidade do professor de incorporar as ferramentas digitais para atingir seus objetivos na abordagem do ensino. Conforme Krumsvik (2011), esse é um desafio para os docentes, especialmente aqueles que não foram formados para alcançar tal competência didática; daí a necessidade de apoio e orientação de pares (VYGOTSKY, 1991), além de formação contínua.

O terceiro componente, estratégias de aprendizagem, assume uma metaperspectiva sobre os dois primeiros, enfatizando as implicações pedagógicas que advêm de planejamento, tutoria de alunos, modelos de diferenciação e cooperação entre escolas que auxiliarão as necessidades dos estudantes em uma estrutura de comunidade de prática (WENGER, 1999). Novamente, Krumsvik (2011) ressalta a necessidade de os professores serem digitalmente competentes para alcançar um potencial pedagógico significativo. 0 quarto componente, formação digital, destaca uma postura do professor em relação aos três primeiros componentes, concentrando-se na influência da revolução digital, o que significa reflexões éticas e morais sobre o papel das tecnologias no desenvolvimento humano, trazendo para o contexto escolar as implicações de viver em uma sociedade digitalizada.

Esse modelo destaca a complexidade do letramento digital com o qual o professor pode ser desafiado a lidar em uma educação digitalizada, e isso requer tempo para atingir um processo de adoção, adaptação, apropriação e inovação (KRUMSVIK, 2011). Nos dois primeiros processos (adoção e adaptação), os professores preocupam-se mais com as habilidades elementares das tecnologias digitais, como o manuseio do computador e seus artefatos. Mesmo que essa etapa configure um desafio para muitos docentes, os limites tecnológicos estão se dissipando em virtude de usos frequentes de smartphones, operações bancárias, e-mail, redes sociais, entre outros. O primeiro obstáculo mais significativo ocorre na apropriação, ou seja, em reconhecer o valor da "invisibilidade" das tecnologias digitais (KRUMSVIK; JONES, 2013) para as affordances no ensino. Essa limitação tem um longo caminho a seguir, pois compreender as tecnologias digitais como possibilidades reais para o ensino, desenvolvendo propostas pedagógicas de forma criativa, redesenhando e desenvolvendo artefatos digitais, exige romper barreiras de infraestrutura e formação.

Outro modelo de base, integrando o conhecimento pedagógico de conteúdo ao conhecimento tecnológico, de forma a potencializar as competências necessárias ao professor como mediador do conhecimento, é a Teoria de TPACK (sigla em inglês para Technological Pedagogical Content Knowledge), elaborada a partir das ideias de Shulman, em 1986. Com o conhecimento pedagógico de conteúdo (PCK), Koehler e Mishra, em 2009, ampliam o conceito para ambientes de aprendizagem equipados com tecnologias digitais. $O$ 
framework $^{5}$ TPACK normalmente se apresenta por meio de um diagrama, conforme Figura 5.

Figura 5 - TPACK: Conhecimento Tecnológico Pedagógico do Conteúdo

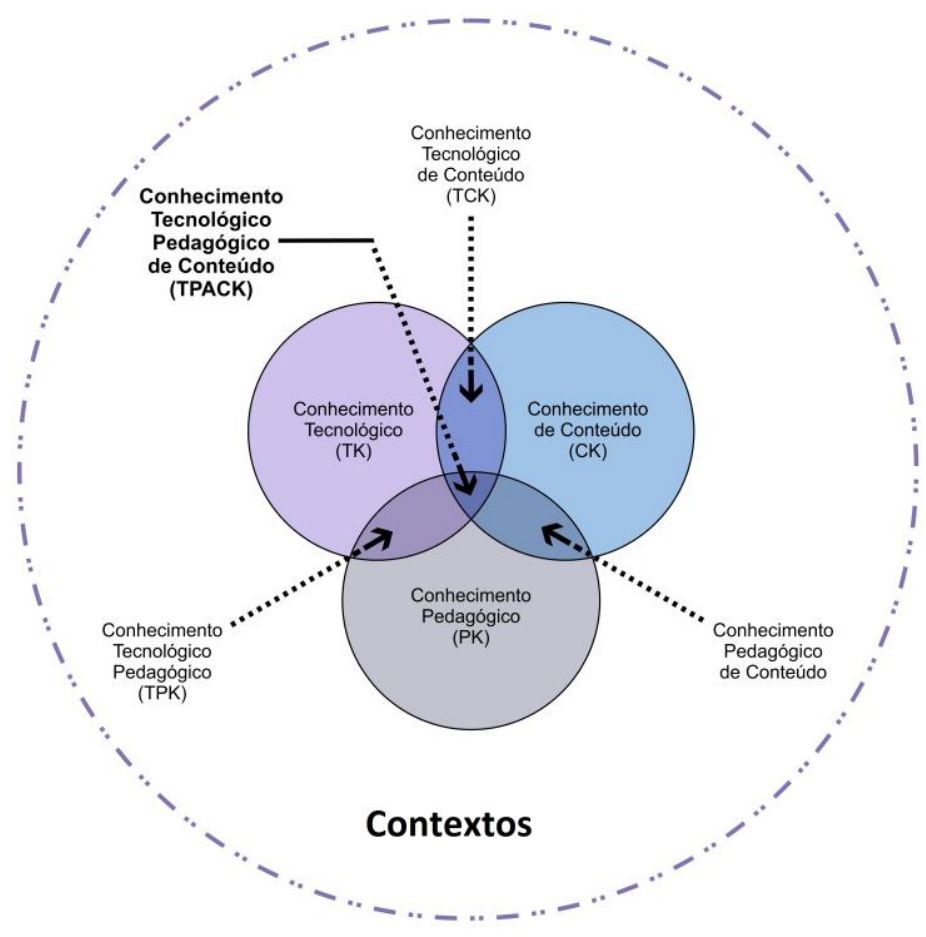

Fonte: Koehler e Mishra (2009, p. 63, tradução nossa).

Nesse modelo, Koehler e Mishra (2009) apresentam três componentes principais do conhecimento dos professores: conteúdo, pedagogia e tecnologia; igualmente importantes são as interações entre eles e os demais domínios. O conhecimento do conteúdo (content knowledge - CK) refere-se ao assunto a ser ensinado ou aprendido; o conhecimento pedagógico (pedagogical knowledge - PK) está relacionado aos processos e práticas de ensino-aprendizagem, como didática e currículo, que contemplam estratégias, objetivos e finalidades educacionais; e o conhecimento tecnológico (technological knowledge - TK), embora apresente riscos devido às constantes evoluções das TDIC, refere-se à maneira de pensar e trabalhar com as tecnologias digitais necessárias em sala de aula. A interseção desses conhecimentos permite entender e descrever os tipos de saberes necessários ao professor para a promoção de uma prática pedagógica mais efetiva em ambientes de aprendizagem com TDIC.

Há inúmeras outras discussões sobre o uso das tecnologias digitais na educação, conforme já apontamos anteriormente, e os desafios são lançados ao ensino tradicional, que se configura na centralidade do professor e que, no entanto, deveria se constituir em uma aprendizagem mais participativa e integrada, em uma relação pessoal e afetiva. Para Moran

\footnotetext{
${ }^{5}$ Embora apresente outros significados, atribuímos a framework o sentido de um conjunto de ideias conectadas para explicar determinado fenômeno; neste caso, a interdependência de conteúdos, pedagogias e tecnologias.
} 
(2013, p. 28), "aprendemos melhor quando vivenciamos, experimentamos, sentimos", e isso requer objetivos bem definidos, ações reflexivas, interação, interiorizações, atitudes diante de tensões e outros processos que nos façam querer aprender.

Todos os materiais apresentados respondem à crescente consciência de que seria interessante aproveitar o potencial das tecnologias para melhorar e inovar a educação. Sem atribuir às tecnologias digitais a responsabilidade de transformar a realidade de um país como o Brasil, colocado no ranking da educação, pela OECD, em 35o lugar, amargando a penúltima posição, a onipresença das TDIC pode contribuir com a participação ativa dos professores para tornar seus alunos competentes para lidar com o mundo contemporâneo.

É importante salientar que as propostas anteriores não representam níveis de proficiência como forma imutável de representatividade de professores, mesmo porque há uma complexidade na qual um docente pode estar em determinado nível para uma situação e em outro nível para diferente contexto. No entanto, acreditamos que as propostas servem para auxiliar o professor e outros setores educacionais, como a supervisão escolar, a seguirem alguns passos para a evolução de sua competência técnica e pedagógica.

A revolução digital certamente avançará, suscitando nas pessoas mudanças em sua forma de viver, trabalhar e estudar. Assim, a preparação digital no domínio da educação requer conhecimentos, além de implicar adaptações e transformações em práticas pedagógicas. Porém, não podemos nos esquecer de que, para que as tecnologias digitais beneficiem os alunos, é preciso combinar programas curriculares, materiais educativos, condições adequadas e, principalmente, tempo e formação que permitam aos professores atingirem um nível de letramento digital para um trabalho pedagógico com qualidade.

\section{Proposta para o letramento digital de professores}

Muitos são os motivos que limitam o educador a incorporar as tecnologias digitais em suas práticas pedagógicas, sobretudo os relacionados à infraestrutura inadequada e à ausência de formação, seja inicial ou continuada. Reiteramos que as situações de aprendizagem informal ainda prevalecem sobre a formação tecnológica dos professores (PAIVA, 2013); no entanto, embora a troca entre pares seja extremamente significativa, são necessárias outras ações que contemplem os modos de uso das tecnologias digitais em sala de aula. A formação continuada precisa estar, efetivamente, nas ações governamentais, inclusive com a promoção de ambientes e espaços para que o professor possa entrar em contato com outros profissionais, permitindo a troca de experiências e a construção de projetos entre eles.

Em vista disso, apresentamos, baseados em Redecker (2017), Puentedura (2006), Koehler e Mishra (2009) e Krumsvik (2014), uma proposta para o letramento digital dos educadores que possibilite o uso das TDIC na elaboração de práticas pedagógicas. Inicialmente, sugerimos a exploração dos recursos tecnológicos digitais, contemplando 
procedimentos e atividades práticas ligadas às tecnologias digitais que podem surtir resultados quando muitos se aventuram a pesquisar experiências que deram certo em sala de aula de outros colegas. Além disso, inclui possibilidades de uso das tecnologias digitais por exploração do comportamento e atitudes de seus próprios alunos, como mostram pesquisas a respeito de momentos de aprendizagem proporcionados pelo uso pedagógico de Facebook, WhatsApp, blogs, entre outros.

A seguir, destacamos caminhos para a instrução, focalizando o aprender a trabalhar com as tecnologias digitais por meio da orientação de teorias, instrumentos didáticos e portais capazes de auxiliar o professor a desenvolver suas atividades. Quanto aos materiais instrucionais, percebemos uma corrente crescente de espaços on-line com a partilha de planejamentos de aulas. O Portal do Professor ${ }^{6}$ (BRASIL, 2018), por exemplo, registrava, no dia 4 de agosto de 2018, um total de 15.171 sugestões de aulas e 840 coleções disponíveis, além de cursos, materiais de estudo, recursos digitais etc. Outro site disponível para o professor, com dicas sobre trabalho com a leitura, como preparar aulas e atividades, é o Redigir, ${ }^{7}$ site de recursos em formato de links, por meio dos quais se pode baixar arquivos de texto, com atividades divididas em "material do aluno" e "material do professor". Embora o uso das tecnologias digitais em sala de aula ainda se mostre em construção, podemos encontrar válidas experiências por meio de material instrucional que possibilite uma aprendizagem aos professores.

Finalizamos nossa proposta com a integração, propondo a construção do conhecimento e a troca de experiências. Esse tipo de aprendizagem requer segurança e a parceria com um par mais experiente (VYGOTSKY, 1991) pode fazer a diferença na aprendizagem por meio das TDIC. O papel desempenhado por esse par, tanto um colega de trabalho quanto o próprio aluno, permitiria uma interação de ajuda mútua, em caso de dúvidas ou necessidades de habilidades mais complexas. Nesse processo, Redecker (2017) observa momentos de experimentação e reflexão para entender melhor as affordances das ferramentas digitais.

Em se tratando de formação de professores para o uso das tecnologias digitais, as trocas entre eles e deles com os alunos contribuiriam para o desenvolvimento de práticas em sala de aula, o que poderia configurar uma comunidade de prática (WENGER, 1999). Paiva (2017) afirma serem as comunidades de prática excelentes fontes de formação de professor, principalmente pela criação de grupos on-line que discutem mudanças em suas práticas pedagógicas. Não podemos nos esquecer, com destaque, da importância do tempo e da infraestrutura para que isso aconteça. São necessários, ainda, momentos de planejamento com uma carga horária adequada e instrumentos tecnológicos que permitam descobrir, experimentar, vivenciar e analisar uma prática pedagógica elaborada por meio das TDIC.

Diálogos e discussões são necessários para descobrir o que pode ser feito a fim de

\footnotetext{
${ }^{6}$ Disponível em: https://goo.gl/1ZHYkQ. Acesso em: 18 jan. 2019.

7 Site do projeto de extensão "Redigir", da Faculdade de Letras da UFMG, sob a coordenação da professora Carla V. Coscarelli. Disponível em: http://www.redigirufmg.org/. Acesso em: 24 jan. 2019.
} 
inserir no ensino estratégias variadas com o uso dessas ferramentas. Assim, o que apresentamos a seguir são recomendações, baseadas neste estudo e voltadas à formação docente no que concerne ao desenvolvimento de um perfil de letramento digital profissional com a exploração significativa das tecnologias digitais em contextos pedagógicos. Apresentamos, então, três caminhos pelos quais o professor poderá desenvolver suas práticas pedagógicas digitais, seja por exploração, instrução ou integração (Figura 6). Destacamos que essas ações incidirão em bons resultados se acompanhadas de investimentos em formação pelos órgãos públicos competentes, além de infraestrutura e uma mudança no tempo diário de planejamento dos docentes.

Figura 6 - Proposta para o letramento digital dos professores para uso profissional

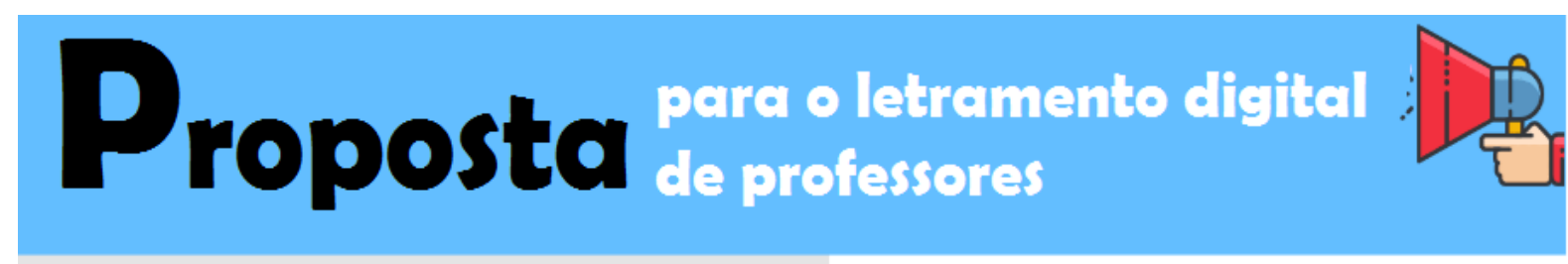

\section{EXPLORAÇÃo}

* Contato com experiências digitais de outros professores.

* Identificação de situações vivenciadas de forma pessoal pelos alunos para possibilidades pedagógicas.

* Experimentação de sites, portais e recursos tecnológicos que permitam um trabalho educacional.
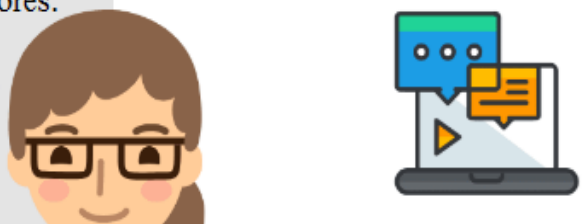

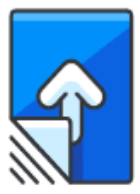

\section{INTEGRAÇÃO}

* Compartilhamento de experiências pedagógicas com as TDIC em sala de aula com outros colegas.

* Participação em comunidades de práticas.

* Publicação de práticas pedagógicas bem-sucedidas em blogs, sites, redes sociais ou em material digital.

\section{INSTRUÇÃO}

* Participação em curso de formação.

* Leituras de livros, revistas, artigos em periódicos e outros materiais que discutem sobre o uso das TDIC na educação.

* Acesso a tutoriais de ferramentas, portais e sites educacionais.

Fonte: Elaborada pela autora.

\section{Conclusões}

A utilização de recursos tecnológicos digitais em educação por si só, como já afirmamos, não garante um trabalho docente eficiente, ou seja, não é uma "fórmula", o que muito se procura para resolver os problemas em educação. Conforme Bruner (2001, p. 67), 
"o ensino real, obviamente, nunca fica confinado a um modelo de aprendizagem ou a um modelo de ensino". No entanto, sabemos que a sala de aula precisa se aproximar do que ocorre fora dela. Assim, um passo importante é o desenvolvimento de um perfil de professor que reconheça uma sociedade tecnológica. Destacamos que essa formação não está associada ao manuseio da máquina, pois tanto em contextos pessoais quanto profissionais, os professores, certamente, já realizam uma gama diversificada de tarefas usando as tecnologias digitais, mesmo que alguns ainda se deparem com dificuldades básicas, como salvar uma imagem.

Sugerimos os processos sintetizados na Figura 6 como caminhos pelos quais os professores poderiam construir ações sobre a natureza das TDIC para mudança de comportamentos, atitudes e práticas em um contexto educacional tecnológico digital. Essa expectativa, assentada em Valente (1993), está ligada à polaridade com que se vai determinar o ensino-aprendizagem mediado pelas tecnologias digitais: computadores, software e aluno ou aluno, software e computadores, como se houvesse uma lacuna entre tecnologias e aluno. Para uma educação na qual essas ferramentas possam se configurar em representação de ideias, comunicação, interação, resolução de problemas, é que apontamos, sugerimos e discutimos, sem estabelecer regras ou condutas, a importância do letramento digital dos professores.

\section{Referências}

ALA-MUTKA, K. Mapping digital competence: towards a conceptual understanding Luxembourg: European Commission: Joint Research Centre: Institute for Prospective Technological Studies, 2011.

ANDERSON, L. W.; KRATHWOHL, D. R. (ed.). A taxonomy for learning, teaching and assessing: a revision of Bloom's Taxonomy of Educational Objectives. New York: Longman, 2001.

BELSHAW, D. A. J. What is "digital literacy"? A pragmatic investigation. 2011. Tese (Doutorado em Educação) - Departamento de Educação, Durham University, 2011.

BRASIL. Ministério da Educação. Base Nacional Comum Curricular: linguagens. Brasília, DF: MEC, 2018.

BRUNER, J. Modelos de mente e modelos de pedagogia. In: BRUNER, J. A cultura da educação. Porto Alegre: Artmed, 2001. p. 59-70

BRYDON, D. Local needs, global contexts: learning new literacies. In: MACIEL, R. F.; ARAUJO, V. A. Formação de professores de línguas: ampliando perspectivas. Jundiaí: Paco, 2011. p. 93109.

BUCKINGHAM, D. Cultura digital, educação midiática e o lugar da escolarização. Educação \& Realidade, Porto Alegre, v. 35, n. 3, p. 37-58, 2010.

BUZATO, M. Letramentos digitais e formação de professores. In: CONGRESSO ÍBEROAMERICANO EDUCAREDE, 2006, São Paulo. Anais [...]. São Paulo: Memorial da América Latina, 2006. 
CANI, J. B. Letramento digital de professores de língua portuguesa: cenários e possibilidades de ensino e de aprendizagem com o uso das TDIC. Tese (Doutorado em Linguística) Universidade Federal de Minas Gerais, Belo Horizonte, 2019.

CASTELLS, M. The internet galaxy: reflections on the internet, business, and society. Oxford: Oxford University Press, 2001. https://doi.org/10.1007/978-3-322-89613-1

COIRO, J.; KNOBEL, M.; LANKSHEAR, C.; LEU, D. J. (Eds.). Handbook of research on new literacies. Routledge, 2014. https://doi.org/10.4324/9781410618894

COSCARELLI, C. V. A leitura em múltiplas fontes: um processo investigativo. Ensino $e$ Tecnologia em Revista, Londrina, v. 1, n. 1, p. 67-79, 2017.

https://doi.org/10.3895/etr.v1n1.5897

CYSNEIROS, P. G. Novas tecnologias na sala de aula: melhoria do ensino ou inovação conservadora. Informática Educativa, v. 12, n. 1, p. 11-24, 1998.

DUDENEY, G.; HOCKLY, N.; PEGRUM, M. Letramentos digitais. Tradução: Marcos Marcionilo. São Paulo: Parábola, 2016.

EUROPE 2020 strategy. European Commission, Brussels, 2016. Disponível em: https://goo.gl/rQk5vF. Acesso em: 18 jan. 2019.

EUROPEAN COMMISSION. Recommendation of the European Parliament and of the Council of 18 December 2006 on key competences for lifelong learning. Official Journal of the European Union, Brussels, 2006. L394/310. Disponível em: https://goo.gl/7N7be7. Acesso em: 21 jan. 2019.

EUROPEAN COMMISSION EDUCATION AND TRAINING. Supporting teacher educators for better learning outcomes. 2013. Disponível em: https://goo.gl/ez9QJi. Acesso em: 21 jan. 2019.

FERRARI, A. Digital competence in practice: an analysis of frameworks. Seville: European Commission: Joint Research Centre: Institute for Prospective Technological Studies, 2012.

FRAILLON, J.; AINLEY, J.; SCHULZ, W.; FRIEDMAN, T.; GEBHARDT, E. Preparing for life in a digital age: The IEA International Computer and Information Literacy Study International Report. Cham: Springer, 2014. https://doi.org/10.1007/978-3-319-14222-7

GASQUE, K. C. G. D. Letramento informacional: pesquisa, reflexão e aprendizagem. Brasília, DF: Universidade de Brasília: Faculdade de Ciência da Informação, 2012.

GILSTER, P. Digital literacy. New York: Wiley Computer Pub, 1997.

HART, C. Doing a Literature Review: Releasing the Social Science Research Imagination; Sage: London, UK, 1998.

HAUGERUD, T. Student teachers learning to teach: The mastery and appropriation of digital technology. Nordic journal of digital literacy, Oslo, v. 6, n. 4, p. 226-238, 2011.

HOFSTETTER, Fred T. Multimedia literacy. McGraw-Hill, Inc., 2001.

INSTITUTO NACIONAL DE TECNOLOGIAS EDUCATIVAS Y DE FORMACIÓN DEL PROFESORADO. Marco común de competencia digital docente. Madrid: Ministerio de Educación, Cultura y Deporte: INTEF, 2017.

JENKINS, $\mathrm{H}$. Confronting the challenges of participatory culture: media education for the $21 \mathrm{st}$ 
century - (Part One). Nordic Journal of Digital Literacy, Oslo, v. 2, n. 1, p. 23-32, 2007.

JESSON, J.; MATHESON, L.; LACEY, F. M. Doing Your Literature Review: Traditional and Systematic Techniques; Sage: London, UK, 2011.

KALANTZIS, M.; COPE, B. "Multiliteracies": new literacies, new learning. Pedagogies, London, v. 4, n. 3, p. 164-195, 2009. https://doi.org/10.1080/15544800903076044

KALANTZIS, M.; COPE, B.; HARVEY A. Assessing multiliteracy and new basics. Assessment in Education, Abingdon, v. 10, n. 1, p. 15-26, 2003. https://doi.org/10.1080/09695940301692

KATO, M. A. No mundo da escrita: uma perspectiva psicolinguística. São Paulo: Ática, 1986.

KEMP, S. Digital in 2018: world's internet users pass the 4 billion mark. Extraído da plataforma We are Social. Disponível em: https://wearesocial.com/blog/2018/01/globaldigital-report-2018. Acesso em: 12 set 2018.

KLEIMAN, A. Os significados do letramento: uma nova perspectiva sobre a prática social da escrita. Campinas: Mercado de Letras, 1995.

KLIEME, E.; HARTIG, J.; RAUCH, D. The concept of competence in educational contexts. In: HARTIG, Johannes; KLIEME, Eckhard; LEUTNER, Detlev (ed.). Assessment of competencies in educational contexts. Göttingen: Hogrefe \& Huber, 2008. p. 3-22.

KOEHLER, M. J.; MISHRA, P. What is technological pedagogical content knowledge? Contemporary Issues in Technology and Teacher Education, v. 9, n. 1, p. 60-70, 2009.

KRESS, G. Literacy in the new media age. New York: Psychology Press, 2003. https://doi.org/10.4324/9780203299234

KRUMSVIK, R. J. Skulen og den digitale læringsrevolusjonen. Oslo: Universitetsforlaget, 2007.

KRUMSVIK, R. J. Digital competence in Norwegian teacher education and schools. Högre utbildning, Oslo, v. 1, n. 1, p. 39-51, 2011.

KRUMSVIK, R. J. Teacher educators' digital competence. Scandinavian Journal of Educational Research, Oslo, v. 58, n. 3, p. 269-280, 2014.

https://doi.org/10.1080/00313831.2012.726273

KRUMSVIK, R. J.; JONES, L. Ö. Teachers' Digital Competence in Upper Secondary School: (Work in Progress). In: INTERNATIONAL CONFERENCE ON INFORMATION COMMUCATION TECHNOLOGIES IN EDUCATION. 2013, Crete. Proceedings [...]. Crete: Southampton Solent University, 2013. p. 171-183.

LANKSHEAR, C. Digital Literacies: concepts, policies and practices. New York: Peter Lang, 2008.

LANKSHEAR, C. Digital literacies: policy, pedagogy and research considerations for education. Nordic Journal of Digital Literacy, Oslo, v. 4, p. 12-24, 2006.

LIVINGSTONE, S. Developing social media literacy: how children learn to interpret risky opportunities on social network sites. Communications, Berlim, v. 39, n. 3, p. 283-303, 2014. https://doi.org/10.1515/commun-2014-0113

LUCENA, S. Culturas digitais e tecnologias móveis na educação. Educar em Revista, Curitiba, v. 32, n. 59, 2016, p. 277-290. https://doi.org/10.1590/0104-4060.43689

MORAN, J. M. Ensino e aprendizagem inovadores com apoio de tecnologias. In: MORAN, J. 
M.; MASETTO, M. T.; BEHERENS, M. A. Novas tecnologias e mediação pedagógica. 21. ed. rev. e atual. Campinas: Papirus, p. 11-72, 2013.

MORTATTI, M.R. L. Educação e letramento. São Paulo: Scielo: Unesp, 2004. https://doi.org/10.7476/9788539302987

NEW LONDON GROUP. A pedagogy of multiliteracies: designing social futures. In: COPE, Bill; KALANTZIS, Mary (org.). Multiliteracies: literacy learning and the design of social futures. New York: Routledge, 2006. p. 60-92.

ORGANIZATION FOR ECONOMIC CO-OPERATION AND DEVELOPMENT. Science, Technology and Innovation Outlook 2018: Adapting to Technological and Societal Disruption. Paris: OECD, 2018.

ORGANIZATION FOR ECONOMIC CO-OPERATION AND DEVELOPMENT. The definition and selection of key competencies: Executive summary. Paris: OECD, 2005. Disponível em: https://goo.gl/8iiHnX. Acesso em: 21 jan. 2019.

PAIVA, V. M. O. A formação do professor para uso da tecnologia. In: SILVA, Kleber Aparecido et al. (org.). A formação de professores de línguas: novos olhares. Campinas: Pontes, v. 2, 2013. p. 209-230.

PAIVA, V. M. O. Aplicativos móveis para aprendizagem de língua inglesa. Polifonia, Cuiabá, v. 24, n. 35/1, p. 10-31, 2017.

PEÑA-LÓPEZ, I. Towards a comprehensive definition of digital skills. ICTlogy, n. 66, 2009.

POTTER, W. J. Media literacy. Thousand Oaks: Sage, 2014.

PUENTEDURA, R. R. SAMR, Learning, and Assessment. Acesso em: 28 nov. 2006. Disponível em: https://goo.gl/oJQ1am. Acesso em: 21 jan. 2018.

RAMOS, S. T. M. Contribuições do curso Elaboração de Material Educacional Digital - Nível Básico para o letramento digital de professores de inglês. Tese (Doutorado em Linguística Aplicada) - Pontifícia Universidade Católica de São Paulo, São Paulo, 2016.

REDECKER, C. European Framework for the Digital Competence of Educators: DigCompEdu. Luxembourg: European Union, 2017. Disponível em: https://goo.gl/ZewrSd. Acesso em: 21 jan. 2019.

ROJO, R. Pedagogia dos multiletramentos: diversidade cultural e de linguagens na escola. In: ROJO, R.; MOURA, E. (org.). Multiletramentos na escola. São Paulo: Parábola, 2012. p. 11-31.

ROJO, R.; MOURA, E. Letramentos, mídias, linguagens. São Paulo: Parábola Editorial, 2019.

RØKENES, F. M.; KRUMSVIK, R. J. Development of student teachers' digital competence in teacher education: a literature review. Nordic Journal of Digital Literacy, Oslo, v. 9, n. 4, p. 250-280, 2014.

SILVA, L. O. Competência tecnológica em foco: a prática de ensino com apoio de ambientes virtuais. Ilha do Desterro, Florianópolis, v.69, n. 1, p.127-140, 2016. https://doi.org/10.5007/2175-8026.2016v69n1p127

SIMONSON, M. R.; MAURER, M.; MONTAG-TORARDI, M.; WHITAKER, M. Development of a standardized test of computer literacy and a computer anxiety index. Journal of educational computing research, v. 3, n. 2, p. 231-247, 1987. 
SOARES, M. Alfabetização e letramento. São Paulo: Contexto, 2011.

SOARES, M. Letramento: um tema em três gêneros. São Paulo: Autêntica, 2014.

SOARES, M. Novas práticas de leitura e escrita: letramento na cibercultura. Educação e Sociedade, Campinas, v. 23, n. 81, p. 143-160, 2002. https://doi.org/10.1590/S0101$\underline{73302002008100008}$

STOKES, S. Visual literacy in teaching and learning: A literature perspective. Electronic Journal for the Integration of Technology in Education, v. 1, n. 1, p. 10-19, 2002.

STREET, B. V. What's "new" in New Literacy Studies? Critical approaches to literacy in theory and practice. Current issues in comparative education, New York, v. 5, n. 2, p. 77-91, 2003.

TAMIM, R. M., BERNARD, R. M., BOROKHOVSKI, E., ABRAMI, P. C.; SCHMID, R. F. What forty years of research says about the impact of technology on learning: A second-order metaanalysis and validation study. Review of Educational Research, v. 81, n. 1, p. 4-28, 2011. https://doi.org/10.3102/0034654310393361

VALENTE, J. A. Computadores e conhecimento: repensando a educação. Campinas: NIED Unicamp, 1993.

VAN DEURSEN, A.; VAN DIJK, J. Internet skills and the digital divide. New Media \& Society, Chicago, v. 13, n. 6, p. 893-911, 2011. https://doi.org/10.1177/1461444810386774

VYGOTSKY, L. S. A formação social da mente. Tradução: José Cipolla Neto, Luis Silveira Menna Barreto, Solange Castro Afeche. 4. ed. São Paulo: Martins Fontes, 1991.

WARSCHAUER, M. A literacy approach to the digital divide. In: M. A. Pereyra (Ed.), Las mulialfabetizaciones em el espacio digital. Malaga, Spain: Ediciones Aljibe, 2011. p. 1-40.

WENGER, E. Communities of practice: learning, meaning and identity. Cambridge: Cambridge University Press, 1999. https://doi.org/10.1017/CBO9780511803932

$=$

Recebido em: 08/09/2019.

Aceito em: 20/01/2020. 